\title{
Azafullerene-based donor-acceptor dyads
}

\author{
Georgios Rotas and Nikos Tagmatarchis* \\ Theoretical and Physical Chemistry Institute, National Hellenic Research Foundation \\ 48 Vassileos Contantinou Avenue, Athens 11635, Greece \\ E-mail: tagmatar@eie.gr
}

Dedicated to Prof. Michael Orfanopoulos on the occasion of his $67^{\text {th }}$ birthday anniversary

DOI: http://dx.doi.org/10.3998/ark.5550190.p008.987

\begin{abstract}
A large amount of research effort focuses on the synthesis and properties of donor-acceptor systems for energy conversion schemes. In this context, fullerenes are novel energy/electron acceptors. Azafullerene $\mathrm{C}_{59} \mathrm{~N}$, which formally arises from the replacement of one carbon of $\mathrm{C}_{60}$ by a nitrogen atom, is derivatized mainly by electrophilic aromatic substitution and Mannich type reactions, thus offering immediate access to diverse dyads. Herein, the aforementioned functionalization methods will be highlighted, especially with regards to the preparation of $\mathrm{C}_{59} \mathrm{~N}$ based donor-acceptor dyads. Particular attention will be given to the energy and charge transfer properties of the $\mathrm{C}_{59} \mathrm{~N}$-based dyads incorporating ferrocene, polycyclic aromatic hydrocarbons, porphyrins, phthalocyanine, corrole and gold nanoparticles.
\end{abstract}

Keywords: Azafullerene; functionalization; donor-acceptor dyads; photophysics; electrochemistry

\section{Table of Contents}

1. Introduction

2. Chemistry of azafullerenes

3. Donor-acceptor dyads

4. Conclusions

5. References 


\section{Introduction}

The first heterofullerene synthesized via the replacement of a carbon atom of an all-carbon fullerene by different species was azafullerene. ${ }^{1}$ The latter replacement effectively led to $\mathrm{n}$-doping of the material, and importantly affected the bonding of the carbon sphere of $\mathrm{C}_{60}$ giving rise to the dimer $\left(\mathrm{C}_{59} \mathrm{~N}\right)_{2}$ with a $\sigma$ bond connecting the two carbons adjacent to nitrogen. n-Doping alters the electronic and optical properties, particularly the charge distribution, electronic structure and energy HOMO-LUMO gap of azafullerenes, as demonstrated by theoretical calculations. ${ }^{2}$ Therefore, azafullerenes are considered suitable materials to be incorporated in advanced technological applications, especially in energy conversion manifolds. In this regard, their development relies on the preparation of diverse hybrids, particularly those in donor-acceptor dyads, and on the evaluation of their properties. In addition, azafullerene-based materials were recently used as acceptors in bulk heterojunction solar cells (BHJSCs) with promising results: a pentaaryl functionalized $\mathrm{C}_{59} \mathrm{~N}$, possessing a raised LUMO as compared to the "benchmark" $\mathrm{PC}_{61} \mathrm{BM}$, matched better to the P3HT donor moiety, ${ }^{3}$ while a bis-functionalized $\mathrm{C}_{59} \mathrm{~N}$, carrying a thiophene and a fused phenylcyclohexyl moiety was also incorporated as an acceptor in BHJSCs, though the performance of the cells have yet to be optimized. ${ }^{4}$

The preparation of bisazafullerene $\left(\mathrm{C}_{59} \mathrm{~N}\right)_{2}$ from the parent fullerene $\mathrm{C}_{60}$ is based on a well described method, ${ }^{1}$ and methods for the chemical modification of $\mathrm{C}_{59} \mathrm{~N}$ have already been comprehensively reviewed. ${ }^{5-7}$ As such, in the current review only some essential aspects will be briefly outlined. The review is organized in three main sections: the first deals with the chemistry of azafullerenes; next, the synthesis of $\mathrm{C}_{59} \mathrm{~N}$-based donor-acceptor dyads and their photophysical evaluation towards charge-transfer processes; and finally, a summary and some concluding remarks are given in the last section of the review.

\section{Chemistry of azafullerene}

Azafullerene in its dimer form $\left(\mathrm{C}_{59} \mathrm{~N}\right)_{2}$ was first synthesized from the $N$-MEM-ketolactam 1 (prepared in two steps from $\left.\mathrm{C}_{60}\right)^{8}$ in refluxing o-dichlorobenzene (ODCB) under inert atmosphere, in the presence of $p$-toluenesulfonic acid ( $p$-TsOH) (Scheme 1). ${ }^{1}$ Owing to the presence of the trivalent nitrogen atom, azafullerene is isolated in its dimeric form $\left(\mathrm{C}_{59} \mathrm{~N}\right)_{2} 2$. Later, an optimization of the reaction conditions led to improved purities and reproducibly higher yield, ${ }^{9}$ allowing easier access to $\left(\mathrm{C}_{59} \mathrm{~N}\right)_{2}$, thus boosting the investigation of its chemistry towards the production of diverse $\mathrm{C}_{59} \mathrm{~N}$ derivatives.

All-carbon fullerenes, whose reaction centers (namely the [6,6] bonds) are in general uniformly dispersed around the sphere, afford in principle, apart from the desirable mono-adduct, also multi-adducts upon derivatization. ${ }^{10}$ In these cases, cycloaddition strategies are the usually employed towards derivatization. On the other hand, in azafullerenes the presence of an $s p^{3}$ carbon next to the nitrogen atom is a reactive center different from the aforementioned described 
$[6,6]$ bonds. Therefore, exploitation of the $s p^{3}$ carbon atom in $\mathrm{C}_{59} \mathrm{~N}$ results in different chemistry from that of all-carbon fullerenes, while at the same time, affords exclusively mono-adducts; multi-adducts, if desired, can subsequently be formed with cycloaddition reactions on the monoadducts. $^{11}$

Chemical derivatization of $\mathrm{C}_{59} \mathrm{~N}$ is based on the fact that upon heating, the intra-dimer bond of $\left(\mathrm{C}_{59} \mathrm{~N}\right)_{2}$ dissociates homolytically towards the azafullerene radical 3 . The latter radical can be either trapped by other radicals to form azafullerene derivatives, ${ }^{12-14}$ such as $\mathbf{5}$, or in the presence of an oxidant, afford the azafullerenyl cation $\mathbf{4}$, which can then react with nucleophiles. The latter method is by far the most widely used for the functionalization of $\mathrm{C}_{59} \mathrm{~N}^{15}$ and has been employed in the two main reactions for the preparation of $\mathrm{C}_{59} \mathrm{~N}$ derivatives, namely, the electrophilic aromatic substitution $\left(\mathrm{S}_{\mathrm{E}} \mathrm{Ar}\right)^{16}$ and the Mannich type reaction, ${ }^{17}$ photoinduced electron transfer reactions of $\mathbf{4}$ have also been reported. ${ }^{18,19}$ In the first, azafullerene reacts with activated aryl compounds, resulting in derivatives $\mathbf{6}$, where the $\mathrm{C}_{59} \mathrm{~N}$ sphere is directly attached to an aromatic ring. In this reaction, the $N$-MEM-ketolactam has also been employed as starting material instead of $\left(\mathrm{C}_{59} \mathrm{~N}\right)_{2}$, yielding the same arylated azafullerene, albeit in lower yield. In the Mannich reaction, enolizable carbonyl compounds such as ketones, malonates, or aldehydes are the functionalization agents, affording the corresponding Mannich bases 7. In both cases, moderate to high yields of $\mathrm{C}_{59} \mathrm{~N}$ derivatives are generally obtained, while the reaction conditions involve in general heating an ODCB solution of $\left(\mathrm{C}_{59} \mathrm{~N}\right)_{2}$ at $150{ }^{\circ} \mathrm{C}$ in the presence of excess $p$ $\mathrm{TsOH}$ and the appropriate reactant (aryl or carbonyl derivative), with a constant stream of air for upto several hours.

\section{Donor-acceptor dyads}

The photophysical properties of azafullerene derivatives such as $\mathbf{6}$ and 7, present both similarities and differences compared to fullerene monoadducts. ${ }^{7,20,21}$ The electronic absorption spectra of azafullerene derivatives are usually similar to that of $\left(\mathrm{C}_{59} \mathrm{~N}\right)_{2}$ and mainly consist of a set of four characteristic bands. A strong $\left(\varepsilon \approx 6 \times 10^{-4} \mathrm{M}^{-1} \mathrm{~cm}^{-1}\right)$ one in the UV region at $320 \mathrm{~nm}$, one of medium intensity at $445 \mathrm{~nm}$, and two weak bands at 720 and $805 \mathrm{~nm}$. The latter is related to the $\mathrm{S}^{0}-\mathrm{S}^{1}$ transition, and its mirror image is reflected in the fluorescence spectra of $\mathrm{C}_{59} \mathrm{~N}$ derivatives, showing a weak $\left(\Phi_{\mathrm{F}} \approx 2.8 \times 10^{-4}\right.$ in toluene) emission band at $815-825 \mathrm{~nm}$. This is a significant difference with $\mathrm{C}_{60}$ mono-adducts, which show a $\mathrm{S}^{0}-\mathrm{S}^{1}$ absorption band at around $690 \mathrm{~nm}$ and emission $\left(\Phi_{\mathrm{F}} \approx 5 \times 10^{-4}\right.$ in toluene) at $\sim 710 \mathrm{~nm}$. Thus, the azafullerene singlet excited state ( $1.52 \mathrm{eV}$ ) lies about $0.27 \mathrm{eV}$ lower in energy than that of functionalized $\mathrm{C}_{60}$, rendering energy transfer to $\mathrm{C}_{59} \mathrm{~N}$ easier. In fact, the $\mathrm{C}_{59} \mathrm{~N}$ fluorescence lifetime of $\sim 0.8 \mathrm{~ns}$ is almost half of those of $\mathrm{C}_{60}$ derivatives, in accordance to the steady state emission behavior. Regarding the $\mathrm{C}_{59} \mathrm{~N}^{1 \mathrm{~S}}$ deactivation, intersystem crossing (ISC) to the triplet manifold occurs, as in the case of $\mathrm{C}_{60}$ derivatives, albeit in lower yield $\left(\Phi_{\mathrm{T}} \approx 0.3\right.$ as compared to $\sim 1$ for $\left.\mathrm{C}_{60}\right)$. The latter reflects the ability of azafullerene to act as photosensitizer for the formation of singlet oxygen upon 
irradiation. ${ }^{22-24}$ Finally, the higher electronegativity of the nitrogen atom is reflected in the electrochemistry of azafullerene derivatives, which usually exhibit three quasi-reversible reduction waves. The first reduction is usually found at more positive potentials than that of $\mathrm{C}_{60}$ derivatives, that is, easier to reduce, thus rendering $\mathrm{C}_{59} \mathrm{~N}$ a potential better electron acceptor in donor acceptor systems.

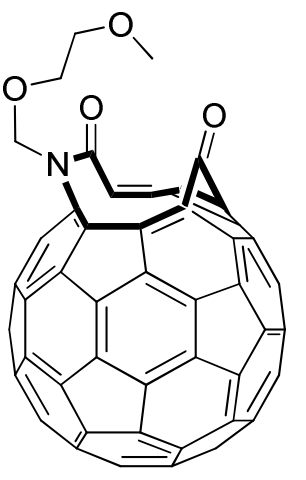

1
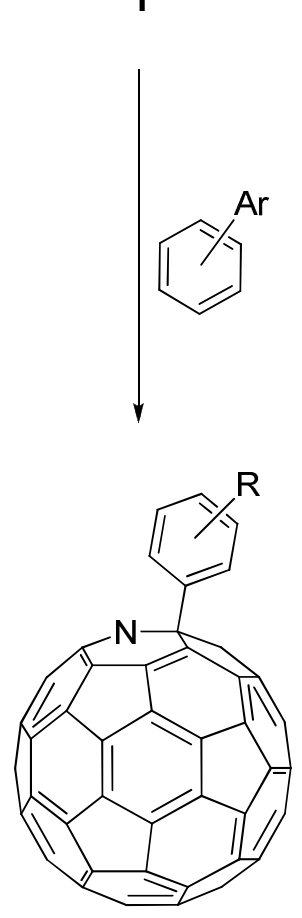

6

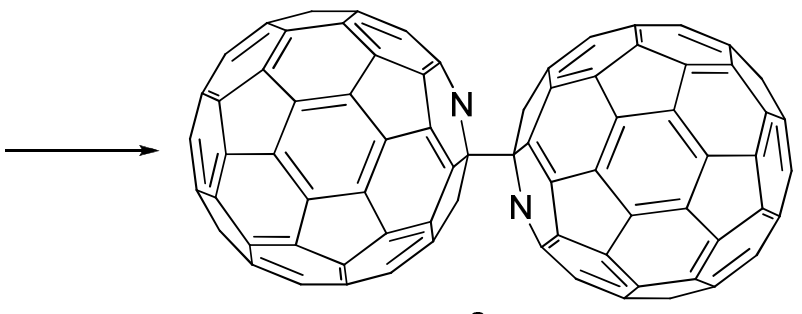

2

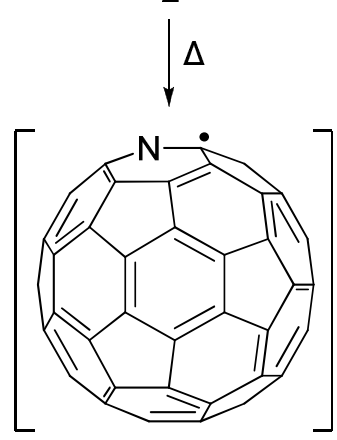

3

[ox]

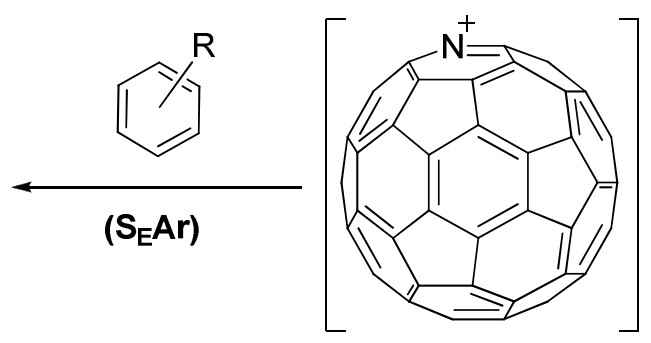

4

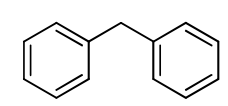

(radical trapping)

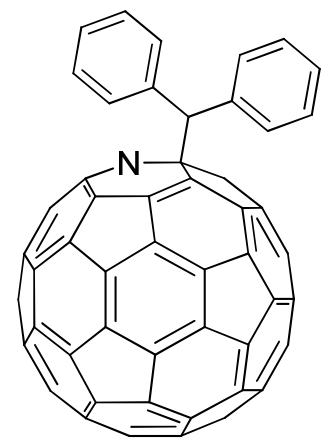

5
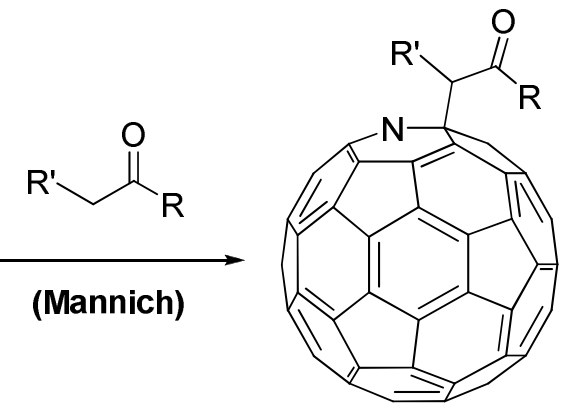

7

Scheme 1. Main routes for the functionalization of azafullerene, either directly from $\left(\mathrm{C}_{59} \mathrm{~N}\right)_{2} \mathbf{2}$ or via the precursor $N$-MEM-ketolactam 1.

Since $\mathrm{C}_{59} \mathrm{~N}$ is by default compared to $\mathrm{C}_{60}$ as acceptor, it would be useful to begin with the properties of an interesting $\mathrm{C}_{59} \mathrm{~N}-\mathrm{C}_{60}$ dyad. By employing the Mannich reaction of $\left(\mathrm{C}_{59} \mathrm{~N}\right)_{2}$ with an equimolar amount of the acetyl functionalized $\mathrm{C}_{60}$ derivative $\mathbf{8}$, dyad 9 (Scheme 2) was 
isolated in $27 \%$ yield. ${ }^{25}$ Concerning its photophysical properties, the absorption spectrum of 9 appears as a superimposition of those of a fullerene monoadduct and $\left(\mathrm{C}_{59} \mathrm{~N}\right)_{2}$. Semiempirical calculations showed that the LUMO of the dyad is located at the $\mathrm{C}_{59} \mathrm{~N}$ core, a fact that is supported by electrochemical measurements, and that the reduction of $\mathrm{C}_{59} \mathrm{~N}$ is easier than that of $\mathrm{C}_{60}$ by about $0.2 \mathrm{~V}$ (in THF). Regarding the excited state properties, the emission spectrum of 9 shows both $\mathrm{C}_{60}$ and $\mathrm{C}_{59} \mathrm{~N}$ emission peaks at 705 and $825 \mathrm{~nm}$, respectively, the former quenched and the latter enhanced relatively to appropriate reference materials. In accordance with this observation, complementary time resolved fluorescence and transient absorption measurements revealed that irradiation of 9 at first results in excitation of both $\mathrm{C}_{60}$ and $\mathrm{C}_{59} \mathrm{~N}$ cores to their singlet excited states. Then, deactivation of $\mathrm{C}_{60}{ }^{1 \mathrm{~S}}$ almost totally occurs through energy transfer to $\mathrm{C}_{59} \mathrm{~N}^{1 \mathrm{~S}}$, which in turn decays through ISC to the azafullerene triplet excited state.

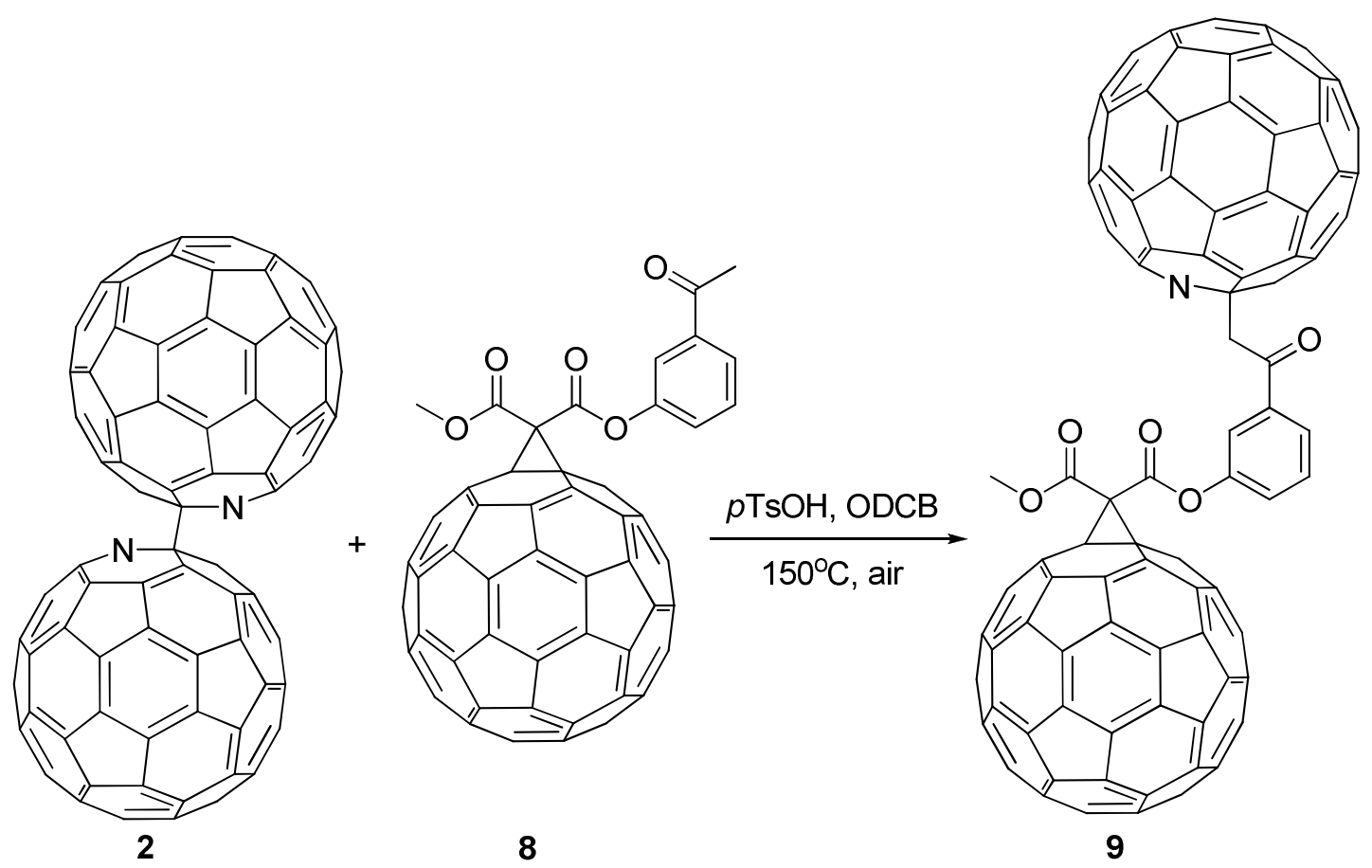

Scheme 2. Synthesis of the $\mathrm{C}_{60}-\mathrm{C}_{59} \mathrm{~N}$ dyad 9 .

The first $\mathrm{C}_{59} \mathrm{~N}$ based donor-acceptor dyad, where a ferrocene moiety is directly attached on the azafullerene sphere, compound $\mathbf{1 0}$ (Figure 1), was also the first fullerene based dyad where the donor is directly connected to the fullerene via a single bond. ${ }^{26}$ The synthesis was accomplished using the $\mathrm{S}_{\mathrm{E}} \mathrm{Ar}$ strategy but in the absence of air flow and $p$ - $\mathrm{TsOH}$, since the role of oxidant was played by ferrocene. With the aid of 25 equivalents of ferrocenium hexafluorophosphate the product was formed in "acceptable yield". Extensive electrochemical studies of the dyad, together with those of reference $\mathrm{C}_{59} \mathrm{~N}$ and ferrocene materials, revealed a significant positive shift of the $\mathrm{Fc}$ oxidation signal (by $183 \mathrm{mV}$ relative to that of the parent ferrocene), together with a minor negative shift of the three $\mathrm{C}_{59} \mathrm{~N}$-originated reduction potentials. 
In addition, the absorption spectrum of the dyad appeared different from a simple superimposition of the component chromophores' spectra. In combination, the above observations suggest significant electronic interactions in the ground state. Concerning the exited state, the characteristic emission of $\mathrm{C}_{59} \mathrm{~N}$ at around $820 \mathrm{~nm}$ was significantly quenched in the dyad, revealing a fast deactivation of the azafullerene singlet excited state. Furthermore, transient absorption spectroscopy showed no evidence of the ferrocene triplet excited state (thus precluding a singlet-triplet energy transfer). In contrast, the existence of an absorption attributed to one electron oxidation of ferrocene suggested the intramolecular charge transfer as the source of the observed azafullerene singlet excited state deactivation. Charge-separated (CS) state lifetimes of $0.4 \mathrm{~ns}$ (in benzonitrile) and $0.27 \mathrm{~ns}$ (in toluene) were calculated.
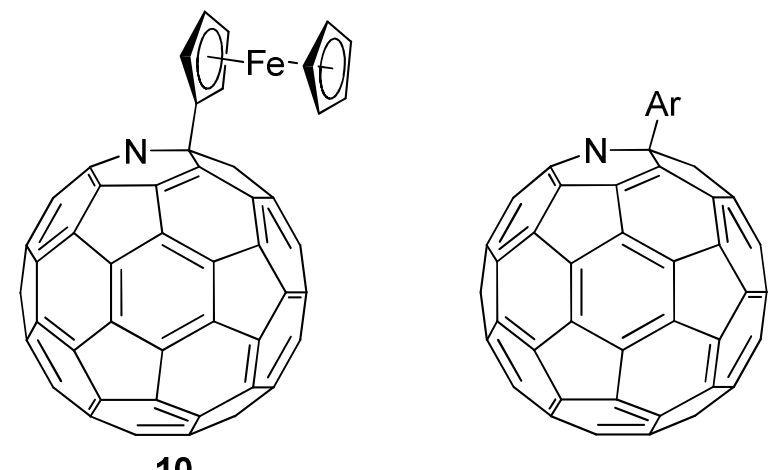

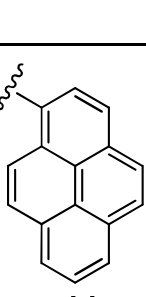

11

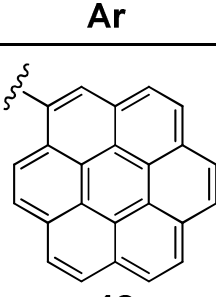

12

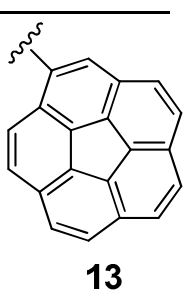

13

Figure 1. $\mathrm{C}_{59} \mathrm{~N}$-based dyads prepared with the $\mathrm{S}_{\mathrm{E}} \mathrm{Ar}$ strategy.

In another work, dyads 11-13 were synthesized, ${ }^{27}$ employing the $S_{\mathrm{E}} \mathrm{Ar}$ strategy (Figure 1). Here, the polycyclic aromatic hydrocarbons (PAHs) pyrene, coronene and corannulene were connected through a single bond with the azafullerene. Briefly, 1 equivalent of the PAH was used in the reaction, affording the products 11-13 in yields 18,17 and $9 \%$, respectively. The electronic interactions of the dyads were monitored with steady state emission spectroscopy, revealing an almost complete quenching of the PAH emission in the visible region. On the other hand, the emission of the azafullerene remains intact, despite the nearly exclusive excitation of the PAH moiety. In addition, the excitation spectra monitoring the emission of the $\mathrm{C}_{59} \mathrm{~N}$ moiety, showed the characteristic absorption patterns of the PAHs. In time-resolved fluorescence, the lifetime of the $\mathrm{C}_{59} \mathrm{~N}$ moiety appears the same as that of the reference $\mathrm{C}_{59} \mathrm{~N}$ material $(\sim 1 \mathrm{~ns})$. In complementary transient absorption measurements, the spectra recorded immediately after the 18 ps lase pulse showed only a broad absorption at $940 \mathrm{~nm}$ (attributed to $\mathrm{C}_{59} \mathrm{~N}^{1 \mathrm{~S}}$ ) and not to that of the $\mathrm{PAH}^{1 \mathrm{~S}}$ expected in the visible region. Thus, all the evidence pointed to the PAHs ultra-fast singlet excited state deactivation via energy transfer to $\mathrm{C}_{59} \mathrm{~N}$.

In the aforementioned $\mathrm{C}_{59} \mathrm{~N}$-based dyads, the $\pi$ electron cloud of the donor lies perpendicular to the azafullerene sphere owing to the rigid structure of the molecule, possibly hampering intramolecular electronic communication. Thus, in a complementary study, a series of aromatic 
systems were used as donors, this time employing the Mannich synthetic approach with acetylsubstituted donors as reactants. In this way, a relatively more flexible linker connects the two chromophores, possibly allowing for a better conformation for electronic communication to occur. Thus, dyads 14-18 were synthesized (Figure 2) in 14-55\% yields, using 7.5-30 equivalents of the appropriate acetyl-substituted compound. ${ }^{28} \mathrm{~A}$ study of the ${ }^{1} \mathrm{H}$ and ${ }^{13} \mathrm{C}$ NMR spectra of the dyads, showed evidence that support both an anti-periplanar (extended, no $\pi-\pi$ interaction) and a folded (efficient $\pi-\pi$ interaction) conformation, leading to the conclusion that a back-folding tendency, attributed to $\pi-\pi$ stacking, is fighting the sterically favored extended conformation, ultimately resulting in rather free rotation. Considering the photophysical properties, absorption spectra of the dyads appear as superimpositions of the component chromophores, thus precluding ground state interactions. Monitoring the excited state features, the near-visible region centered donor emission (340-400 nm) of the dyads 14-18 was found quenched by a factor of 3-7 relative to that of the acetyl-functionalized aromatics (and a factor of as large as 1100 relative to the parent aromatics). Regarding the azafullerene emission $(\sim 825$ $\mathrm{nm}$ ), the same observations as in the case of dyads 11-13 mentioned above, irrespectively of the solvent polarity, led to the conclusion of an efficient intramolecular energy transfer. This observation was verified with transient absorption measurements. The singlet excited state of the fluorophore appears at low time scales with short lifetimes $(\sim 100 \mathrm{ps})$, while later, the $\mathrm{C}_{59} \mathrm{~N}^{1 \mathrm{~S}}$ appears $(\sim 940 \mathrm{~nm})$ as a meta-stable condition which decays via ISC to the triplet excited state.
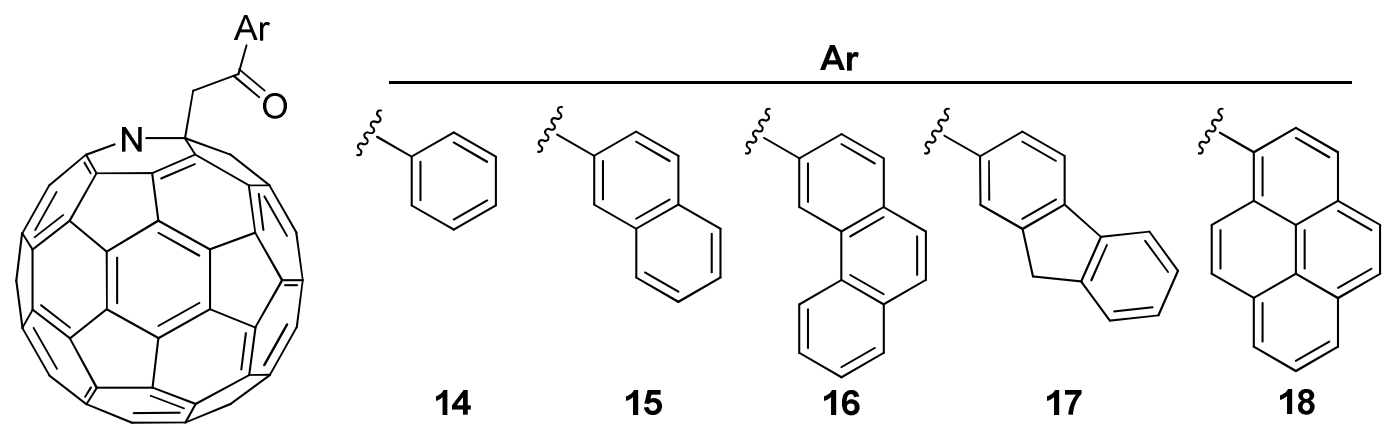

Figure 2. (Poly)aromatic hydrocarbon $\mathrm{C}_{59} \mathrm{~N}$-based derivatives prepared via the Mannich strategy.

Porphyrins are widely known as excellent electron donors and in this context, numerous porphyrin-fullerene donor-acceptor systems have been synthesized and their properties towards efficient charge separation have been investigated. The first work on covalently linked porphyrin-azafullerene systems involved the synthesis and photophysical study of dyads $\mathbf{1 9}$ and 20 (Figure 3). ${ }^{29}$ The syntheses were accomplished with the Mannich strategy, employing an equimolar amount of a malonate or an acetyl functionalized tetraphenyl porphyrin (TPP) in moderate yields. Concerning their photophysical properties, the strong porphyrin emission appears quenched by a factor of around 50 in both dyads. Interestingly, while the observed 
quenching rate of $\mathbf{2 0}$ increases with the polarity of the solvent employed (attributed to through bond electron transfer), that of $\mathbf{1 9}$ remains intact (attributed to solvent-assisted through space electron transfer, owing to greater configurational freedom). Transient absorption measurements showed $\mathrm{TPP}^{1 \mathrm{~S}}$ lifetimes of $\sim 0.35 \mathrm{~ns}$ for 19 (independent of the solvent) while for $\mathbf{2 0}$, TPP ${ }^{1 \mathrm{~S}}$ lifetimes of 0.19 and $0.08 \mathrm{~ns}$ were observed in THF and more polar benzonitrile, respectively. The kinetics of the charge separated states, as monitored from the decays of TPP ${ }^{\bullet+}(600-700 \mathrm{~nm})$ and $\mathrm{C}_{59} \mathrm{~N}^{--}(1010 \mathrm{~nm})$, revealed shortening of radical ion pair lifetimes on increasing solvent polarity (445 and $362 \mathrm{~ns}$ for 19, and 260 and $155 \mathrm{~ns}$ for 20, in THF and benzonitrile, respectively). This observation is rationalized in terms of the Marcus theory of electron transfer, where the charge-separation rate decreases on increasing the driving force for systems that lie in the inverted region.

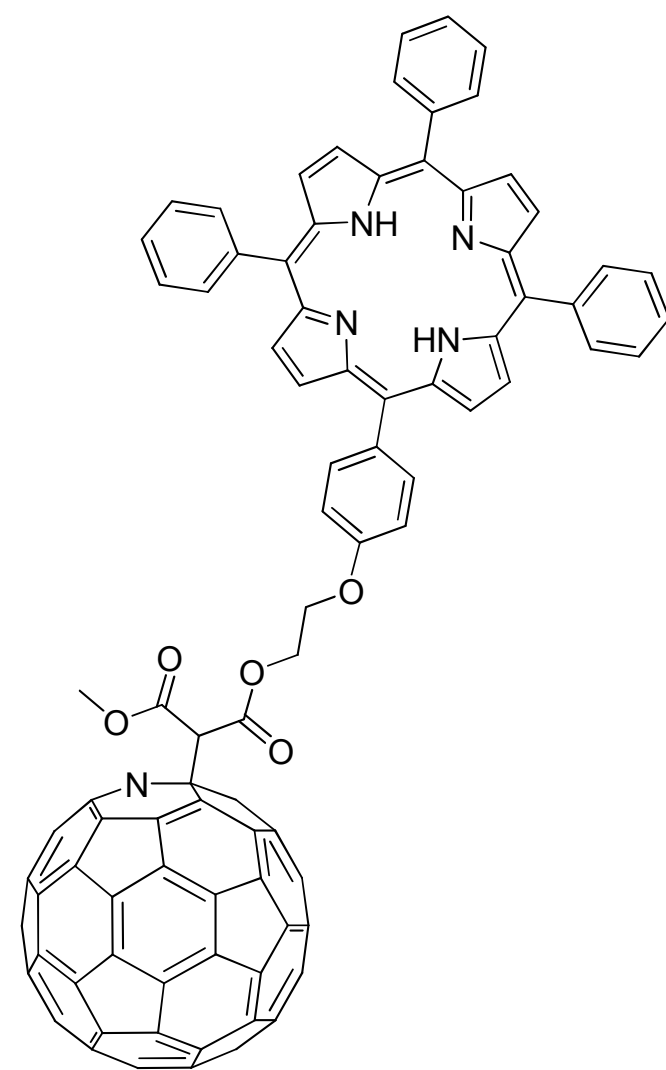

19

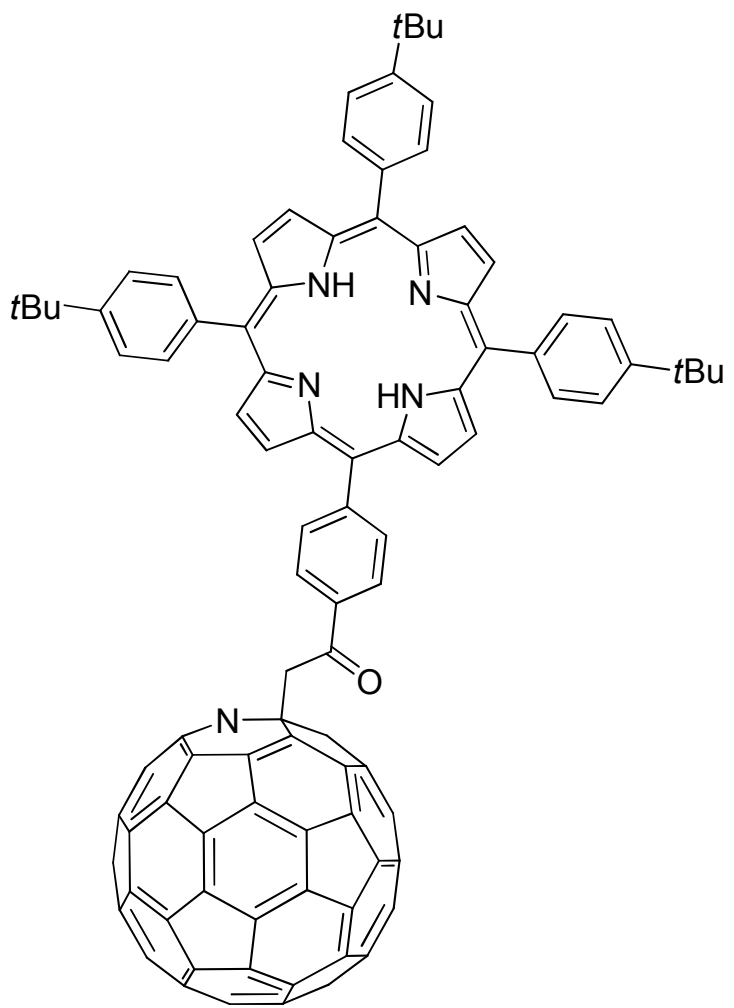

20

Figure 3. Covalently attached porphyrins to azafullerene; $\mathrm{C}_{59} \mathrm{~N}$-porphyrin dyads $\mathbf{1 9}$ and $\mathbf{2 0}$.

A different synthetic route towards $\mathrm{C}_{59} \mathrm{~N}$-based donor-acceptor dyads involved at first the synthesis of an azafullerene derivative bearing a functional group, which subsequently reacts with an appropriately functionalized donor. Thus, the carboxylic acid functionalized $\mathrm{C}_{59} \mathrm{~N} 21$ (Scheme 3), prepared in 55\% yield by the Mannich reaction of $\left(\mathrm{C}_{59} \mathrm{~N}\right)_{2}$ with 50 equivalents of 
$t$-butyl malonate $)^{30}$ enabled the use of hydroxyl or amino-functionalized donor derivatives for the preparation of dyads, while at the same time, the relatively harsh conditions of the $\mathrm{C}_{59} \mathrm{~N}$ functionalization $\left(150{ }^{\circ} \mathrm{C}, p\right.$-TsOH, air) were replaced by the smooth ones of a condensation reaction. In this context, an equimolar amount of $\mathbf{2 1}$ and a hydroxyl functionalized phthalocyanine $\left(\mathrm{H}_{2} \mathrm{Pc}\right)$ were condensed with the aid of EDCI/HOBt towards dyad 22 (34\% yield). While weak ground state interactions between the two chromophores were observed, the 128-fold quenching of the $\mathrm{H}_{2} \mathrm{Pc}$ emission revealed strong excited state interactions. Monitoring the azafullerene emission, in non-polar toluene was found enhanced (suggesting energy transfer from $\mathrm{H}_{2} \mathrm{Pc}$ ) relative to the reference $\mathrm{C}_{59} \mathrm{~N}$, while in polar benzonitrile was found quenched, thus suggesting electron transfer. Interestingly, electrochemical measurements revealed a somewhat lower charge separated state energy than that of $\mathrm{C}_{59} \mathrm{~N}^{1 \mathrm{~S}}-\mathrm{H}_{2} \mathrm{Pc}$, suggesting a possible charge transfer from azafullerene singlet excited state (apart from $\mathrm{H}_{2} \mathrm{Pc}^{1 \mathrm{~S}}$ ) in polar solvents. Complementary transient absorption measurements revealed quite different deactivation behavior of the dyad after excitation in toluene and in benzonitrile. In toluene, absence of charge separated state formation was verified and a sequence of energy transfer reactions and transitions were found to occur towards the $\mathrm{H}_{2} \mathrm{Pc}$ triplet excited state $\left(\mathrm{C}_{59} \mathrm{~N}-\mathrm{H}_{2} \mathrm{Pc}^{1 \mathrm{~S}} \rightarrow \mathrm{C}_{59} \mathrm{~N}^{1 \mathrm{~S}}-\mathrm{H}_{2} \mathrm{Pc} \rightarrow\right.$ $\left.\mathrm{C}_{59} \mathrm{~N}^{1 \mathrm{~T}}-\mathrm{H}_{2} \mathrm{Pc} \rightarrow \mathrm{C}_{59} \mathrm{~N}-\mathrm{H}_{2} \mathrm{Pc}^{1 \mathrm{~T}}\right)$. A completely different deactivation pathway was observed in benzonitrile, where the formation of the charge separated state dominates in deactivation, but the main pathway is again a multi-step one, including energy transfer to $\mathrm{C}_{59} \mathrm{~N}$ prior to the electron transfer $\left(\mathrm{C}_{59} \mathrm{~N}-\mathrm{H}_{2} \mathrm{Pc}^{1 \mathrm{~S}} \rightarrow \mathrm{C}_{59} \mathrm{~N}^{1 \mathrm{~S}}-\mathrm{H}_{2} \mathrm{Pc} \rightarrow \mathrm{C}_{59} \mathrm{~N}^{\cdot-}-\mathrm{H}_{2} \mathrm{Pc}^{\bullet+}\right)$. Also, the photophysical properties of $\mathrm{C}_{59} \mathrm{~N}-\mathrm{H}_{2} \mathrm{Pc} 22$ were compared to those of a previously reported $\mathrm{C}_{60}-\mathrm{H}_{2} \mathrm{Pc}$ dyad. ${ }^{31}$ The lower energy of $\mathrm{C}_{59} \mathrm{~N}^{1 \mathrm{~S}}$ compared to that of $\mathrm{C}_{60}{ }^{1 \mathrm{~S}}$ explained the ease of energy transfer in 22 even in benzonitrile, since $\mathrm{C}_{59} \mathrm{~N}^{1 \mathrm{~S}}-\mathrm{H}_{2} \mathrm{Pc}$ lies energetically lower than $\mathrm{C}_{59} \mathrm{~N}-\mathrm{H}_{2} \mathrm{Pc}^{1 \mathrm{~S}}$, while the opposite was observed in the $\mathrm{C}_{60}-\mathrm{H}_{2} \mathrm{Pc}$ dyad. Thus, although the charge separated states' lifetimes of 22 and $\mathrm{C}_{60}-\mathrm{H}_{2} \mathrm{Pc}$ in benzonitrile were comparable (190 and $320 \mathrm{ps}$, respectively), the electron transfer process is much slower (15 ps) in 22 than in $\mathrm{C}_{60}-\mathrm{H}_{2} \mathrm{Pc}(2 \mathrm{ps})$, a fact attributed to the extra step of energy transfer.

Carboxylic acid functionalized $\mathrm{C}_{59} \mathrm{~N} 21$ was also used for the synthesis of the $\mathrm{C}_{59} \mathrm{~N}$-corrole dyad $\mathbf{2 3}^{32}$ (Scheme 3), through a condensation reaction of an equimolar amount of $\mathbf{2 1}$ and an amino-functionalized corrole in $8 \%$ yield. The strong emission of the corrole at around $660 \mathrm{~nm}$ was quenched in the dyad by a factor of 20-116 depending of the solvent employed, while a similar trend was observed in emission lifetime experiments. Interestingly, transient absorption measurements of dyad $\mathbf{2 3}$ showed the electron transfer to be the route for the observed deactivation of corrole singlet excited state, in polar and non-polar solvents alike. Monitoring the process in $o$-xylene, toluene, anisole, 2-methyl-THF and benzonitrile, a predictable gradual decrease of the corrole singlet excited state lifetime was observed on increasing solvent polarity (from $166 \mathrm{ps}$ to $16 \mathrm{ps}$, as monitored by the corrole ${ }^{1 \mathrm{~S}} 1240 \mathrm{~nm}$ transient absorption) and in parallel, a gradual decrease of the radical ion pair $\mathrm{C}_{59} \mathrm{~N}^{--}$-corrole ${ }^{\circ+}$ lifetime (from $1 \mathrm{~ns}$ to $65 \mathrm{ps}$, monitoring the $\mathrm{C}_{59} \mathrm{~N}^{--}$absorption at $1040 \mathrm{~nm}$ ). The latter trend of diminishing CS lifetime upon 
increasing solvent polarity was rationalized, as in the cases of $\mathbf{1 9}$ and $\mathbf{2 0}$ (see above), using the Marcus theory of electron transfer.

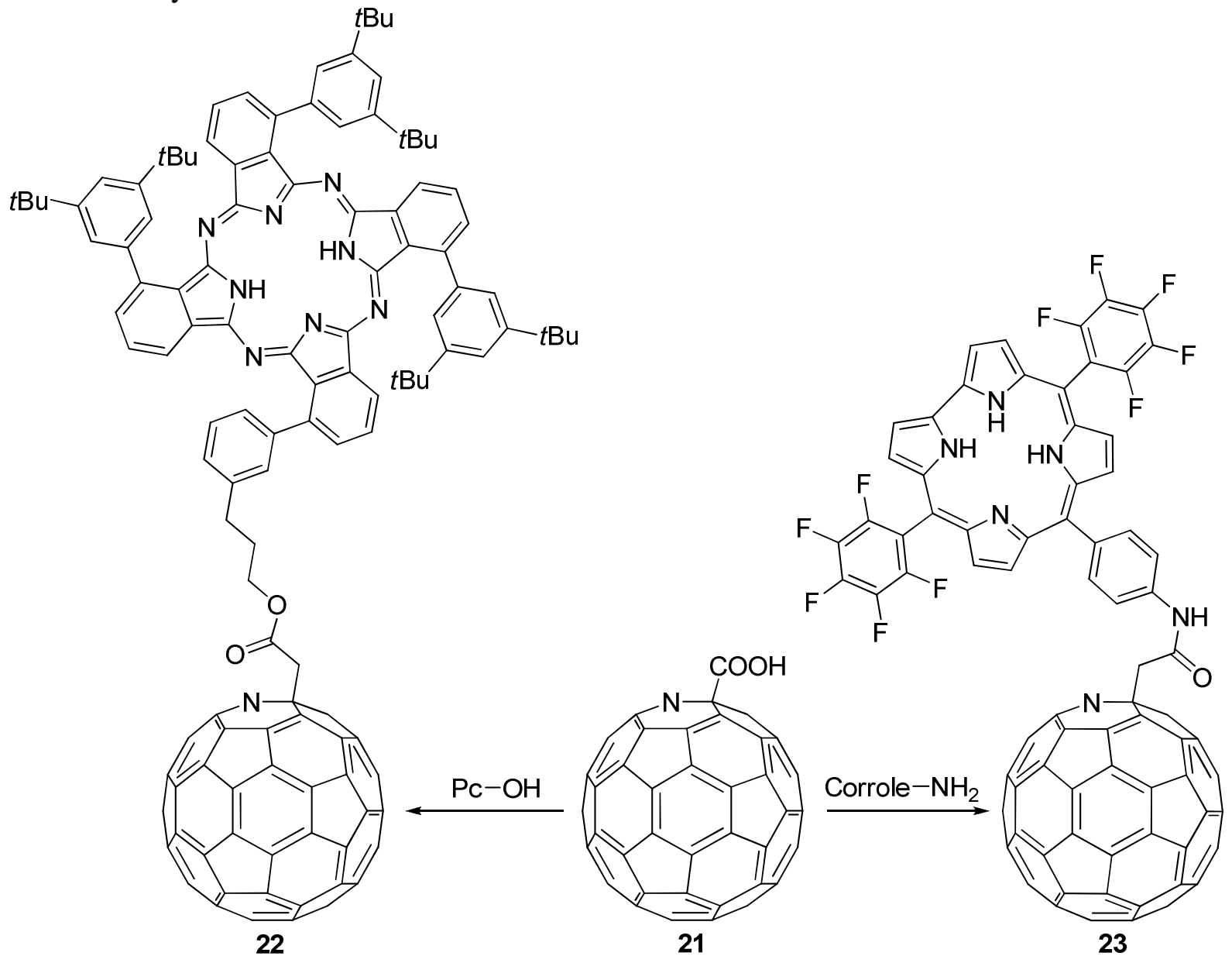

Scheme 3. Use of carboxylic acid $\mathrm{C}_{59} \mathrm{~N}$-based derivative 21 in the preparation of donor-acceptor systems.

In a rather different approach to those described above, the properties of a supramolecular assemply of an azafullerene derivative with a zinc porphyrin (ZnTPP) where studied. ${ }^{33} \mathrm{~A}$ pyridine functionalized $\mathrm{C}_{59} \mathrm{~N}$ (prepared in $78 \%$ yield by the Mannich approach using 200 equivalents of 4-acetylpyridine) together with an equimolar amount of ZnTPP were dissolved in deuterated ODCB to study by NMR spectroscopy the formation of the complex 24 (Figure 4). The spectrum showed no evidence of free ZnTPP, as well as a remarkable upfield shift of the $\alpha$-pyridine protons' signal by $5 \mathrm{ppm}$, verifying an almost complete complexation of the two chromophores. Furthermore, ZnTPP absorption spectrum showed a red shift (2-4 nm) of both $Q$ and Soret bands on adding $\mathrm{C}_{59} \mathrm{~N}$-pyridine. Steady state emission of ZnTPP also showed a gradual quenching (up to 25 fold), while time resolved measurements turned emission lifetime from a monoexponential of $2 \mathrm{~ns}$ for free ZnTPP, to a biexponential of 1.9 and $0.12-0.15 \mathrm{~ns}$, with 
increasing contribution of the short-lived component, on increasing $\mathrm{C}_{59} \mathrm{~N}$-pyridine concentration in non-coordinating solvents (toluene, ODCB). The original emission properties of ZnTPP were restored on addition of THF or pyridine, suggesting the dissolution of the complex 24 in the presence of coordinating compounds. Correlating the emission quenching with the $\mathrm{C}_{59} \mathrm{~N}$-pyridine concentration, association constants for the formation of 24 of 9500 and $11700 \mathrm{M}^{-1}$ for toluene and ODCB, respectively were derived. Concerning the deactivation mechanism of $\mathrm{ZnTPP}^{1 \mathrm{~S}}$, an increase of the $\mathrm{C}_{59} \mathrm{~N}$ emission together with the ZnTPP emission quenching in toluene indicated energy transfer $\left(\mathrm{ZnTPP}{ }^{1 \mathrm{~S}}-\mathrm{C}_{59} \mathrm{~N} \rightarrow \mathrm{ZnTPP}-\mathrm{C}_{59} \mathrm{~N}^{1 \mathrm{~S}}\right)$, a fact that was reinforced by transient absorption measurements, where ZnTPP $-\mathrm{C}_{59} \mathrm{~N}^{1 \mathrm{~S}}$ was found to further decay to ZnTPP $-\mathrm{C}_{59} \mathrm{~N}^{1 \mathrm{~T}}$. This observation was set in contrast to the mechanism of a similar $\mathrm{C}_{60}-\mathrm{ZnTPP}$ supramolecular dyad, ${ }^{34}$ where electron transfer dominates even in toluene. On the other hand, charge transfer was the deactivation path in the more polar ODCB. Here, the formation of the charge-separated state is energetically more favorable and its formation was verified by the presence of the $\mathrm{C}_{59} \mathrm{~N}^{-}$ and $\mathrm{ZnTPP}^{\circ+}$ transient absorption peaks, yielding a radical ion pair lifetime of $145 \mathrm{~ns}$.

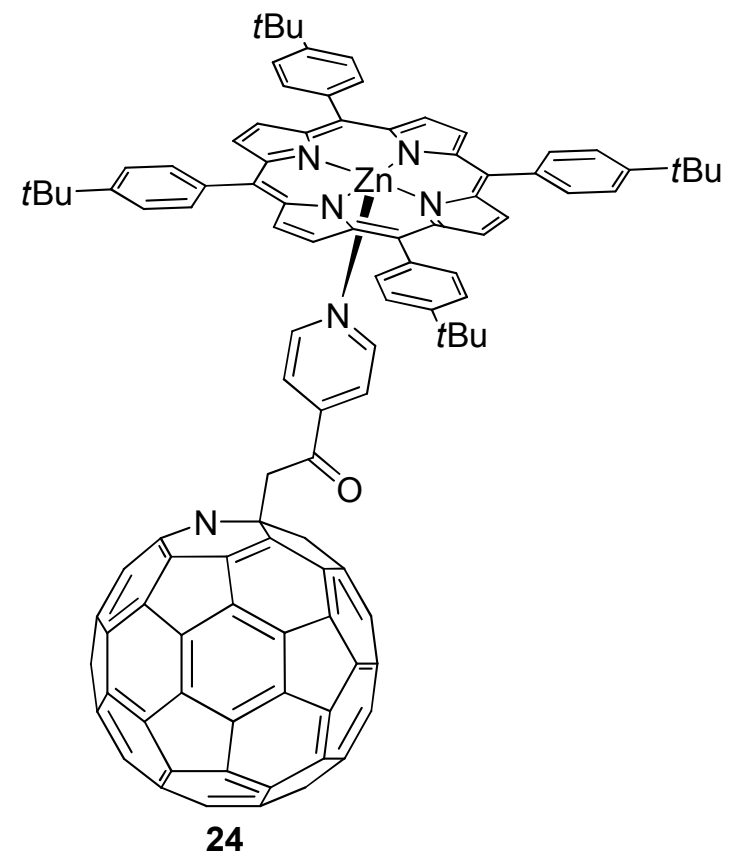

Figure 4. $\mathrm{C}_{59} \mathrm{~N}$-porphyrin supramolecular dyad.

Finally, an organic-inorganic nanohybrid, where the azafullerene was decorated with gold nanoparticles, has been recently synthesized and its photophysical properties investigated. ${ }^{35}$ At first, the dithiolane functionalized azafullerene 25 was synthesized in $85 \%$ yield from a condensation reaction between a phenolic $\mathrm{C}_{59} \mathrm{~N}$ derivative and lipoic acid. Nanohybrid 26 was then prepared by a ligand exchange reaction between dodecanothiol stabilized Au nanoparticles (AuNPs) and 25 (Figure 6). High-resolution transmission electron microscopy (HR-TEM) 
images of 26 revealed a broad particle size distribution with two populations of 2.2 and $4.5 \mathrm{~nm}$ average particle size, in contrast to AuNPs where a narrow distribution centered at $2 \mathrm{~nm}$ was the case. Furthermore, a non-uniform electron density of the large nanoparticles in $\mathbf{2 6}$, together with the presence of some aggregates, suggested an azafullerene-induced aggregation of nanoparticles towards large agglomerates. ${ }^{1} \mathrm{H}$ NMR measurements of $\mathbf{2 6}$ showed a $1.6 \%$ w/w loading of $\mathbf{2 5}$. In the absorption spectrum, the surface plasmon band (SPB) of AuNPs was red-shifted in 26, suggesting closer inter-particle proximity, while the small loading of $\mathbf{2 5}$ did not allow the characteristic azafullerene peaks to appear. Steady state fluorescence measurements showed a weak broad emission band at $805 \mathrm{~nm}$, after excitation either at $330 \mathrm{~nm}$ (where azafullerene absorbs) or at $500 \mathrm{~nm}$ (negligible $\mathrm{C}_{59} \mathrm{~N}$ absorption) in toluene, blue-shifted and enhanced relative to that of an equimolar $\mathrm{C}_{59} \mathrm{~N}$ solution of 25, suggesting energy transfer from AuNPs to $\mathrm{C}_{59} \mathrm{~N}$. Transient absorption measurements showed that after excitation, together with the AuNPs excitation relaxation $(2.5 \mathrm{ps})$, a non-intense absorption appears, which is attributed to $\mathrm{C}_{59} \mathrm{~N}^{1 \mathrm{~S}}$, indicative of energy transfer.
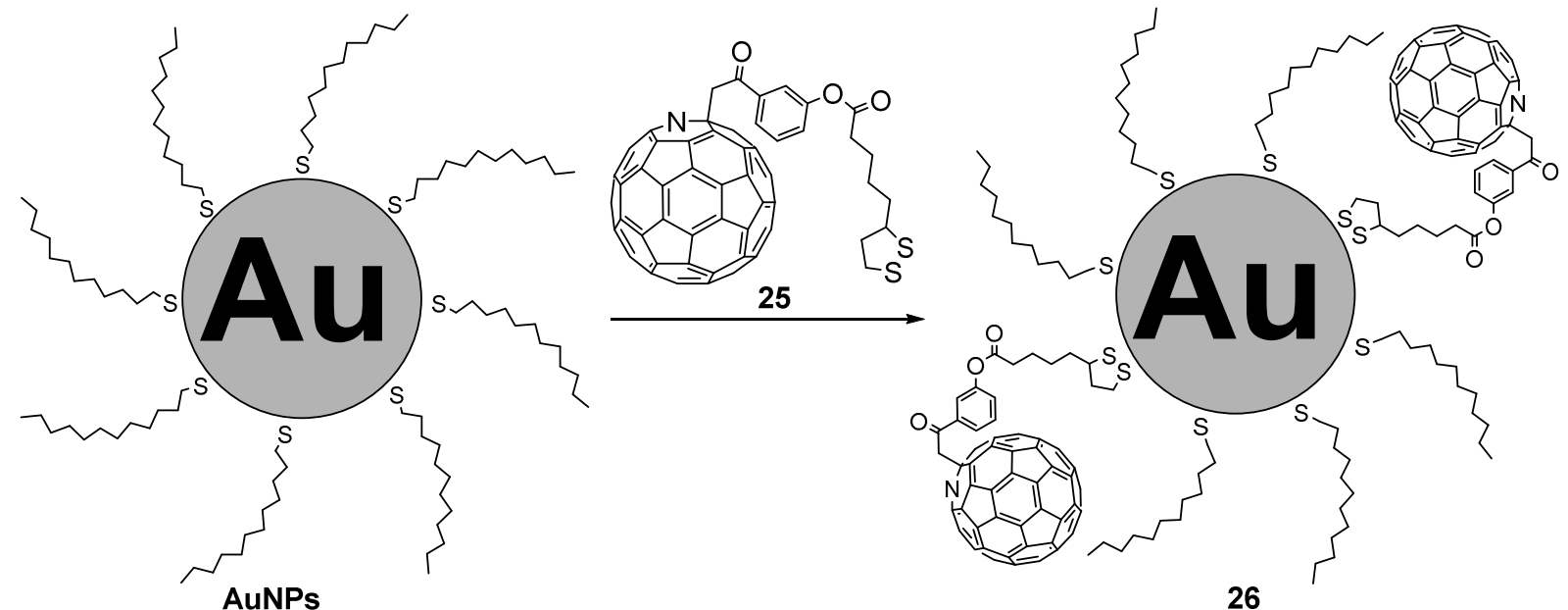

Scheme 4. Preparation of $\mathrm{C}_{59} \mathrm{~N}$ decorated with gold nanoparticles.

\section{Conclusions}

The preparation of azafullerene-based donor-acceptor systems via the two main functionalization strategies, electrophilic aromatic substitution and Mannich type reactions, has been reviewed. The variety of common functional groups that the donor can bear (acetyl, aryl, hydroxyl, amino, carboxy) to react with the bisazafullerene (or a simple azafullerene derivative), facilitates access to the desirable dyads. Although relatively few, azafullerene-based donor-acceptor systems show interesting properties on intra-molecular energy or electron transfer. In particular, owing to the low energy of azafullerene singlet excited state, a fast (ultra-fast in many cases) energy transfer 
from the donor excited state is commonly observed in non-polar media, although charge transfer has also been detected. On the other hand, in polar media, stabilization of the charge-separated state leads to the formation of radical ion-pairs. In any case, energy or charge transfer to $\mathrm{C}_{59} \mathrm{~N}$ is the preferred option for the deactivation of the donor excited state. Without doubt, this particular research area can be further expanded when considering the possibility of incorporating multichromophoric arrays of diverse electron donors to azafullerene.

\section{References}

1. Hummelen, J. C.; Knight, B.; Pavlovich, J.; González, R.; Wudl, F. Science 1995, 269, 1554. http://dx.doi.org/10.1126/science.269.5230.1554

2. Xie, R.-H.; Bryant, G. W.; Sun, G.; Kar, T.; Chen, Z.; Smith, V. H.; Araki, Y.; Tagmatarchis, N.; Shinohara, H.; Ito, O. Phys. Rev. B 2004, 69, 201403.

http://dx.doi.org/10.1103/PhysRevB.69.201403

3. Wessendorf, C. D.; Eigler, R.; Eigler, S.; Hanisch, J.; Hirsch, A.; Ahlswede, E. Sol. Energy Mater. Sol. Cells 2015, 132, 450.

http://dx.doi.org/10.1016/j.solmat.2014.09.038

4. Xiao, Z.; He, D.; Zuo, C.; Gan, L.; Ding, L. RSC Adv. 2014, 4, 24029. http://dx.doi.org/10.1039/c4ra02757d

5. Vostrowsky, O.; Hirsch, A. Chem. Rev. 2006, 106, 5191. http://dx.doi.org/10.1021/cr050561e

6. Hirsch, A.; Nuber, B. Acc. Chem. Res. 1999, 32, 795. http://dx.doi.org/10.1021/ar980113b

7. Hummelen, J.; Bellavia-Lund, C.; Wudl, F. In Topics in Current Chemistry: Fullerenes and Related Structures; Hirsch, A., Ed.; Springer Berlin Heidelberg: 1999; Vol. 199, p 93. http://dx.doi.org/10.1007/3-540-68117-5 3

8. Hummelen, J. C.; Prato, M.; Wudl, F. J. Am. Chem. Soc. 1995, 117, 7003. http://dx.doi.org/10.1021/ja00131a024

9. Reuther, U.; Hirsch, A. Carbon 2000, 38, 1539. http://dx.doi.org/10.1016/S0008-6223(00)00053-1

10. Hirsch, A.; Brettreich, M. Fullerenes - Chemistry and Reactions; Wiley-VCH Verlag, Weinheim, 2005; pp 289-302. http://dx.doi.org/10.1002/3527603492.ch10

11. Hauke, F.; Hirsch, A. Chem. Commun. 2001, 1316. http://dx.doi.org/10.1039/b103169b

12. Bellavia-Lund, C.; González, R.; Hummelen, J. C.; Hicks, R. G.; Sastre, A.; Wudl, F. J. Am. Chem. Soc. 1997, 119, 2946. http://dx.doi.org/10.1021/ja964447c

13. Vougioukalakis, G. C.; Orfanopoulos, M. Tetrahedron Lett. 2003, 44, 8649. 
http://dx.doi.org/10.1016/j.tetlet.2003.09.158

14. Tzirakis, M. D.; Orfanopoulos, M. Chem. Rev. 2013, 113, 5262. http://dx.doi.org/10.1021/cr300475r

15. Hauke, F.; Hirsch, A. Tetrahedron 2001, 57, 3697. http://dx.doi.org/10.1016/S0040-4020(01)00235-6

16. Nuber, B.; Hirsch, A. Chem. Commun. 1998, 405. http://dx.doi.org/10.1039/a707704a

17. Hauke, F.; Hirsch, A. Chem. Commun. 1999, 2199. http://dx.doi.org/10.1039/a906711f

18. Vougioukalakis, G. C.; Orfanopoulos, M. J. Am. Chem. Soc. 2004, 126, 15956. http://dx.doi.org/10.1021/ja045495x

19. Roubelakis, M. M.; Vougioukalakis, G. C.; Nye, L. C.; Drewello, T.; Orfanopoulos, M. Tetrahedron 2010, 66, 9363. http://dx.doi.org/10.1016/j.tet.2010.10.006

20. Guldi, D.; Hauke, F.; Hirsch, A. Res. Chem. Intermed. 2002, 28, 817. http://dx.doi.org/10.1163/15685670260469438

21. Hauke, F.; Vostrowsky, O.; Hirsch, A.; Quaranta, A.; Leibl, W.; Leach, S.; Edge, R.; Navaratnam, S.; Bensasson, R. V. Chem. Eur. J. 2006, 12, 4813. http://dx.doi.org/10.1002/chem.200501536

22. Tagmatarchis, N.; Shinohara, H. Org. Lett. 2000, 2, 3551. http://dx.doi.org/10.1021/ol0002121

23. Tagmatarchis, N.; Shinohara, H.; Fujitsuka, M.; Ito, O. J. Org. Chem. 2001, 66, 8026. http://dx.doi.org/10.1021/jo0104678

24. Eigler, R.; Heinemann, F. W.; Hirsch, A. Chem. Commun. 2014, 50, 2021. http://dx.doi.org/10.1039/c3cc48461k

25. Hauke, F.; Herranz, M. A.; Echegoyen, L.; Guldi, D.; Hirsch, A.; Atalick, S. Chem. Commun. 2004, 600. http://dx.doi.org/10.1039/b315006b

26. Hauke, F.; Hirsch, A.; Liu, S.-G.; Echegoyen, L.; Swartz, A.; Luo, C.; Guldi, D. M. ChemPhysChem 2002, 3, 195. http://dx.doi.org/10.1002/1439-7641(20020215)3:2<195::AID-CPHC195>3.0.CO;2-C

27. Hauke, F.; Atalick, S.; Guldi, D. M.; Mack, J.; Scott, L. T.; Hirsch, A. Chem. Commun. 2004, 766. http://dx.doi.org/10.1039/b316139k

28. Hauke, F.; Hirsch, A.; Atalick, S.; Guldi, D. Eur. J. Org. Chem. 2005, 1741. http://dx.doi.org/10.1002/ejoc.200400771

29. Hauke, F.; Atalick, S.; Guldi, D. M.; Hirsch, A. Tetrahedron 2006, 62, 1923. http://dx.doi.org/10.1016/j.tet.2005.04.078

30. Rotas, G.; Ranta, J.; Efimov, A.; Niemi, M.; Lemmetyinen, H.; Tkachenko, N.; Tagmatarchis, N. ChemPhysChem 2012, 13, 1246. 
http://dx.doi.org/10.1002/cphc.201101029

31. Lemmetyinen, H.; Kumpulainen, T.; Niemi, M.; Efimov, A.; Ranta, J.; Stranius, K.; Tkachenko, N. V. Photochem. Photobiol. Sci. 2010, 9, 949. http://dx.doi.org/10.1039/c0pp00059k

32. Rotas, G.; Charalambidis, G.; Glatzl, L.; Gryko, D. T.; Kahnt, A.; Coutsolelos, A. G.; Tagmatarchis, N. Chem. Commun. 2013, 49, 9128. http://dx.doi.org/10.1039/c3cc45191g

33. Hauke, F.; Swartz, A.; Guldi, D. M.; Hirsch, A. J. Mater. Chem. 2002, 12, 2088. http://dx.doi.org/10.1039/b202060b

34. Da Ros, T.; Prato, M.; Guldi, D. M.; Ruzzi, M.; Pasimeni, L. Chem. Eur. J. 2001, 7, 816. http://dx.doi.org/10.1002/1521-3765(20010216)7:4<816::AID-CHEM816>3.0.CO;2-A

35. Rotas, G.; Niemi, M.; Tkachenko, N. V.; Zhao, S.; Shinohara, H.; Tagmatarchis, N. Chem. Eur. J. 2014, 20, 14729.

http://dx.doi.org/10.1002/chem.201403517

\section{Authors}

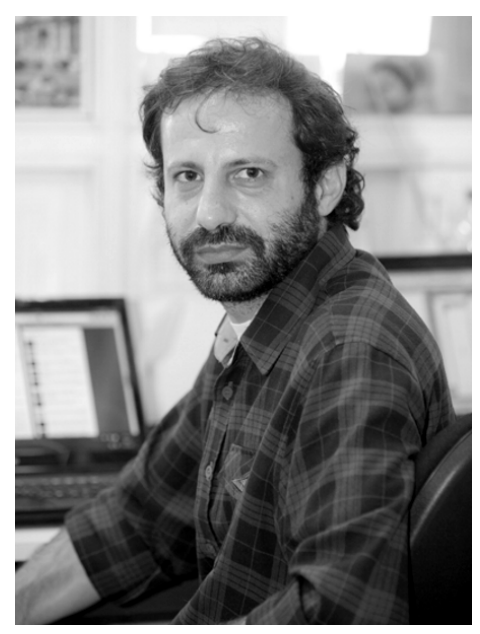

Georgios Rotas was born in Athens in 1977, obtained his BSc on chemistry in 1998 and PhD degree on organic synthesis in 2005 from the University of Ioannina. In 2006 he joined the group of Dr. N. Tagmatarchis at the Theoretical and Physical Chemistry Institute, National Hellenic Research Foundation, and his research interests fall in the design, synthesis and study of electroactive fullerene, azafullerene and graphene-based materials. 


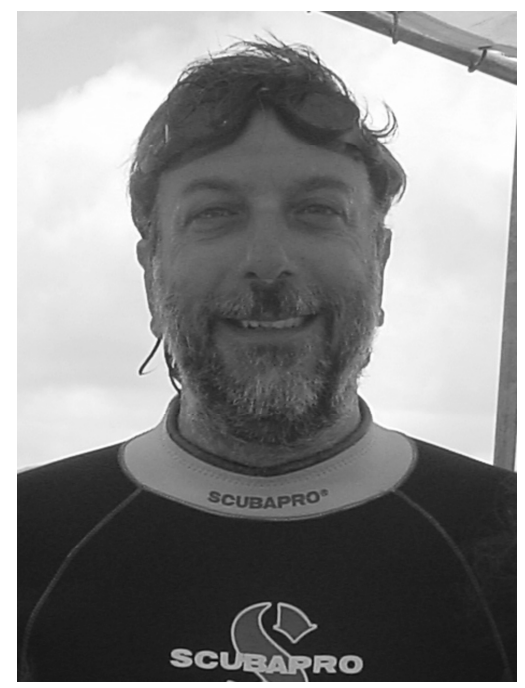

Nikos Tagmatarchis is Director of Research in the Theoretical and Physical Chemistry Institute at the National Hellenic Research Foundation, in Athens, Greece. His research interests focus on the chemistry of carbon-based nanostructured materials in the context of electron transfer processes for diverse nanotechnological applications. His accomplishments in the area are reflected in a plethora of publications, citations and numerous invitations at conferences. He was recipient of the European Young Investigator Award (2004), Visiting Professor at the Chinese Academy of Sciences (2011) and Invited Fellow by the Japan Society for the Promotion of Science in Japan (2012-2013). 